\title{
Prevalence of Peanut Allergy in Offspring of Peanut Farmers
}

\author{
Amanda Jagdis' ${ }^{1}$, Gary Liss ${ }^{2}$, Soheila Maleki³ ${ }^{\text {, Peter Vadas }}{ }^{4}$ \\ ${ }^{1}$ Division of Allergy and Clinical Immunology, St. Michael's Hospital, University of Toronto, Toronto, Canada \\ ${ }^{2}$ Dalla Lana School of Public Health, Gage Occupational and Environmental Health Unit, University of Toronto, \\ Toronto, Canada \\ ${ }^{3}$ Food Allergy Research, USDA-ARS-SRRC, New Orleans, USA \\ ${ }^{4}$ Division of Allergy and Clinical Immunology, St. Michael's Hospital, University of Toronto, Toronto, Canada \\ Email: amanda.jagdis@mail.utoronto.ca, gary.liss@utoronto.ca, soheila.maleki@ars.usda.gov, \\ vadasp@smh.ca
}

Received 3 October 2014; revised 16 November 2014; accepted 3 December 2014

Copyright (C) 2015 by authors and Scientific Research Publishing Inc.

This work is licensed under the Creative Commons Attribution International License (CC BY).

http://creativecommons.org/licenses/by/4.0/

(c) (i) Open Access

\begin{abstract}
Introduction: While exposure to environmental peanut during infancy appears to promote sensitization by the epicutaneous route, early and frequent peanut ingestion during infancy may prevent peanut allergy through oral tolerance. Due to parental occupation, the offspring of peanut farmers are likely exposed to peanut protein in their environment, but they may also have early introduction into their diet due to ready access. The purpose of this study was to determine the prevalence of peanut allergy in offspring of peanut farmers. Methods: A survey was mailed by the National Peanut Board to peanut farmers in the United States collecting information on peanut consumption, peanut reactions, physician-confirmed peanut allergy (PA), epinephrine auto-injector prescription and history of other allergies in offspring. Egg allergy (EA) served as a comparator to peanut allergy. Results: Of 10,349 households surveyed, 1050 responses were received (2493 offspring, participation rate $10 \%$ ). The self-reported prevalence of peanut allergy in the general population in the USA is $0.9 \%, 1.3 \%$, and $0.7 \%$ for children 0 - 5 years, 6 - 10 years, and 11 - 17 years, respectively. In offspring of peanut farmers, PA vs EA was reported in $3.69 \%(10 / 271)$ vs $2.6 \%(7 / 271), 2.8 \%(14 / 493)$ vs $2.0 \%(10 / 493)$, and $1.48 \%(37 / 2493)$ vs $1.4 \%(35 / 2493)$ of offspring $\leq 10$ years, offspring $\leq 15$ years and all offspring, respectively. Physician-confirmed PA was reported in $3.3 \%(9 / 271), 2.6 \%(13 / 493)$, and $1.24 \%(31 / 2493)$ in the three groups, respectively. Physician-confirmed PA with epinephrine auto-injector prescription was reported in $1.8 \%$ $(5 / 271), 1.8 \%(9 / 493)$, and $0.68 \%(17 / 2493)$ in the three groups, respectively. Conclusions: We found that the self-reported prevalence of peanut allergy in offspring of peanut farmers was similar to that reported in the general population. This is a unique population that may provide insight into factors that influence development of peanut allergy.
\end{abstract}


Keywords

Peanut Allergy, Prevalence, Sensitization, Peanut Farmers Offspring

\section{Introduction}

The prevalence of peanut allergy among children in North America and the United Kingdom has increased during the past two decades and is currently estimated at 1.68\% in Canada [1], 1.4\% in the United States (US) [2], and $1.8 \%$ in the United Kingdom (UK) [3]. Peanut allergy (PA) typically begins in early childhood and is often persistent; it remits in approximately $20 \%$ of patients by age 5 [4]. Peanut allergy is a relevant public health issue as it is implicated in the majority of fatal food-related anaphylactic reactions [5]-[7]. Most children react upon their first apparent oral exposure to peanuts, indicating that sensitization likely occurs prior to the first known oral introduction [8] [9]. Given the morbidity associated with PA, identifying the mechanism of primary sensitization is necessary in order to develop effective preventive strategies.

Exposure to traces of peanut in the household environment is a risk factor for sensitization; children who develop PA have a ten-fold higher level of household peanut consumption compared to children without PA [10]. This dose-response relationship was observed between environmental (i.e. non-oral) peanut exposure and the development of PA. A defective epidermal barrier increases the risk of peanut sensitization. Early childhood eczema, use of topical peanut oil-containing skin preparations [11] and loss of function mutations in the filaggrin gene [12] have been associated with development of PA. These observations suggest that cutaneous allergen exposure promotes sensitization. Recently, filaggrin mutations have been shown to increase the risk of food sensitization in the first year of life, but not food challenge-proven allergy, suggesting that additional influences are required to shift from sensitization to clinical allergy [13].

In contrast, early high-dose oral exposure may promote acquisition of tolerance to allergens [14] [15]. Murine experiments have demonstrated development of immune and clinical tolerance with high dose oral exposure to both ovalbumin and peanut protein [14] [15]. In humans, the adjusted prevalence of PA is about 5 times less among Ashkenazi children in Israel where peanuts are consumed earlier, more frequently and in greater quantity than in Ashkenazi children in the United Kingdom [16].

The purpose of this study was to examine the prevalence of PA in offspring of peanut farmers in the United States. Children with early exposure to the farming environment have a lower prevalence of atopy than children from non-farming families [17]. Early life exposure to stables and farm milk in particular have been associated with a lower prevalence of asthma, hay fever and allergic sensitization [18] due to multiple immune modulatory mechanisms that are not yet fully understood. The offspring of peanut farmers may be somewhat unique in regard to their environmental and oral exposure to peanut. Due to the nature of parental occupation, offspring of peanut farmers are likely exposed to peanut protein in their environment. For the same reason, however, peanut may be a more readily accessible food source for offspring of peanut farmers than for other individuals, which may affect the timing and frequency of oral exposure. The aim of this study was to examine the prevalence of PA among offspring of peanut farmers compared to the prevalence in the general population.

\section{Methods}

\subsection{Study Population and Survey Method}

A cross-sectional survey of peanut farmers and their families was conducted in the United States. A total of 10,349 surveys were distributed by mail to peanut farmers as an insert in a quarterly newsletter by the National Peanut Board in August 2006. Ethics approval was not required for this anonymous survey study.

\subsection{Survey Questions}

The survey collected demographic data from parents on the number and ages of offspring in each family, as well as the history of asthma, atopic dermatitis, pollen allergy, allergen immunotherapy, and a history of food allergies in both offspring and parents. Data were collected for each offspring regarding the age at which peanut was introduced into the diet, the number of times per week peanut was consumed, and any history of peanut reac- 
tions. For each offspring with a history of reaction to peanut, survey participants were asked to report the age of first peanut reaction, time of onset of reaction following ingestion of peanut, associated symptoms, treatment required, whether PA was diagnosed by a physician, and whether an epinephrine auto-injector was prescribed.

Survey participants were asked about each of the following symptoms during their offspring's peanut reactions: a) itching, hives, welts, redness of skin, b) swelling of eyes, lips, ears, tongue, hands, feet or genitals, c) runny or stuffy nose, d) red, itchy, watery eyes, e) trouble swallowing, hoarse voice, tightness in throat, itching inside mouth, f) wheezing, cough, tightness in chest, shortness of breath, g) nausea, vomiting, stomach cramps, diarrhea, h) dizziness, lightheadedness, faintness, loss of consciousness.

\subsection{Definition of PA and Other Atopic Conditions}

Three definitions of PA of varying stringency were examined. In order of increasing stringency, we considered: i) how many of your children have eaten peanuts and had an allergic reaction? ii) meets i) and, has the child's peanut allergy been confirmed by a physician? iii) meets ii) and, has your peanut-allergic child been prescribed an epinephrine auto-injector such as Epipen ${ }^{\circledR}$ or TwinJect ${ }^{\circledR}$ ?

Asthma, eczema and parental allergies were defined as any history of these conditions diagnosed by a physician. Pollen allergy, immunotherapy and other food allergy were defined as any history of the condition recalled by the survey participant.

\subsection{Statistical Analysis}

Outcomes and analyses were performed at the level of the family. Separate analyses were performed for offspring age $\leq 10$ years, offspring age $\leq 15$ years, and for all offspring of respondents, in overlapping (not mutually exclusive) groups.

\section{Results}

\subsection{Questionnaire Response Rate and Demographic Features}

A total of 1050 survey responses were completed and returned by peanut farmers, with a total of 2651 offspring. Due to survey wording (the survey allowed answers for up to 5 offspring only, even for families who had $\geq 6$ offspring), the analyses were restricted to families with 5 or fewer offspring, yielding a total of 2493 offspring. The mail-out survey response rate was 10\% (1050 survey responses, 10,349 surveys mailed). The distribution of the number of offspring per family included one child (14\%), two, three, four, five and six offspring in $43.8 \%$, $25.5 \%, 9.7 \%, 3.4 \%$ and $2.6 \%$ of families, respectively. The age distribution of the offspring ranged from $0.1-67$ years, with mean age of 26.2 years (SD 14.7), as shown in Figure 1.

\subsection{Peanut Allergy}

Reported outcomes are shown in Table 1. The self-reported rate of PA among offspring of US peanut farmers aged 10 years and under was 3.69\% (10/271). Of these cases, 3.3\% (9/271) were confirmed by a physician, and 1.8\% (5/271) were both confirmed by a physician and prescribed an epinephrine auto-injector. In offspring 15 years and under, the reported rate of PA was 2.8\% (14/493). Of these cases, 2.6\% (13/493) were physician-confirmed, and 1.8\% (9/493) were both physician-confirmed and prescribed an epinephrine auto-injector. Finally, among all offspring, the reported rate of PA was 1.48\% (37/2493), with 1.24\% (31/2493) physician-confirmed and $0.68 \%$ (17/2493) physician-confirmed and prescribed an epinephrine auto-injector.

Of the 17 cases who had both physician-confirmed PA and epinephrine auto-injector prescription, 14/17 (82\%) experienced their initial reaction at age $<5$ years.

The reported clinical manifestations of peanut allergy included cutaneous symptoms (15/17, 88\%), angioedema $(10 / 17,59 \%)$, respiratory $(8 / 17,47 \%)$, nasal/ocular (6/17, 35\%), oropharyngeal (6/17, 35\%), gastrointestinal (5/17, 29\%), and cardiovascular symptoms (one case only).

\subsection{Peanut Exposure}

Only $1.0 \%$ of families reported that their offspring had not ingested peanuts. The age of first peanut exposure varied with $39.2 \%$ reporting estimated peanut introduction by age $1 \%$ and $81.9 \%$ by age 3, as shown in Figure 2 . 


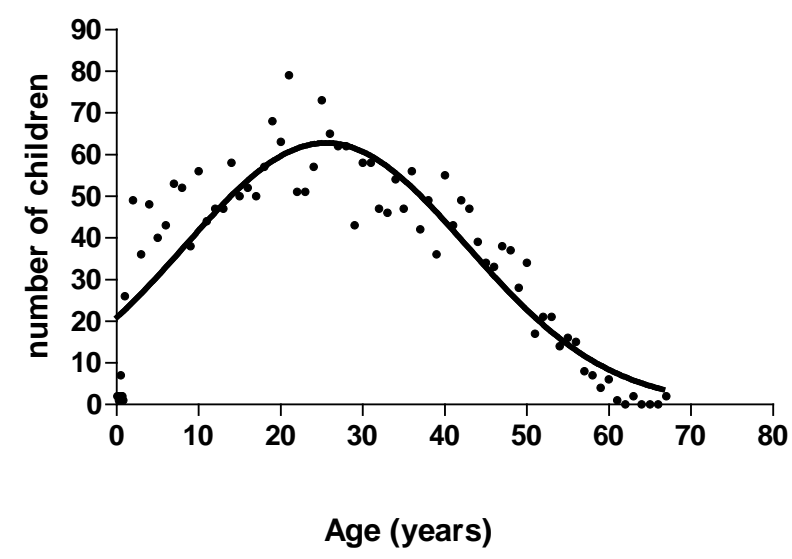

Figure 1. Age distribution of peanut farmers' offspring (range 0.1 to 67 years; mean $26.2 \pm 14.7$ ).

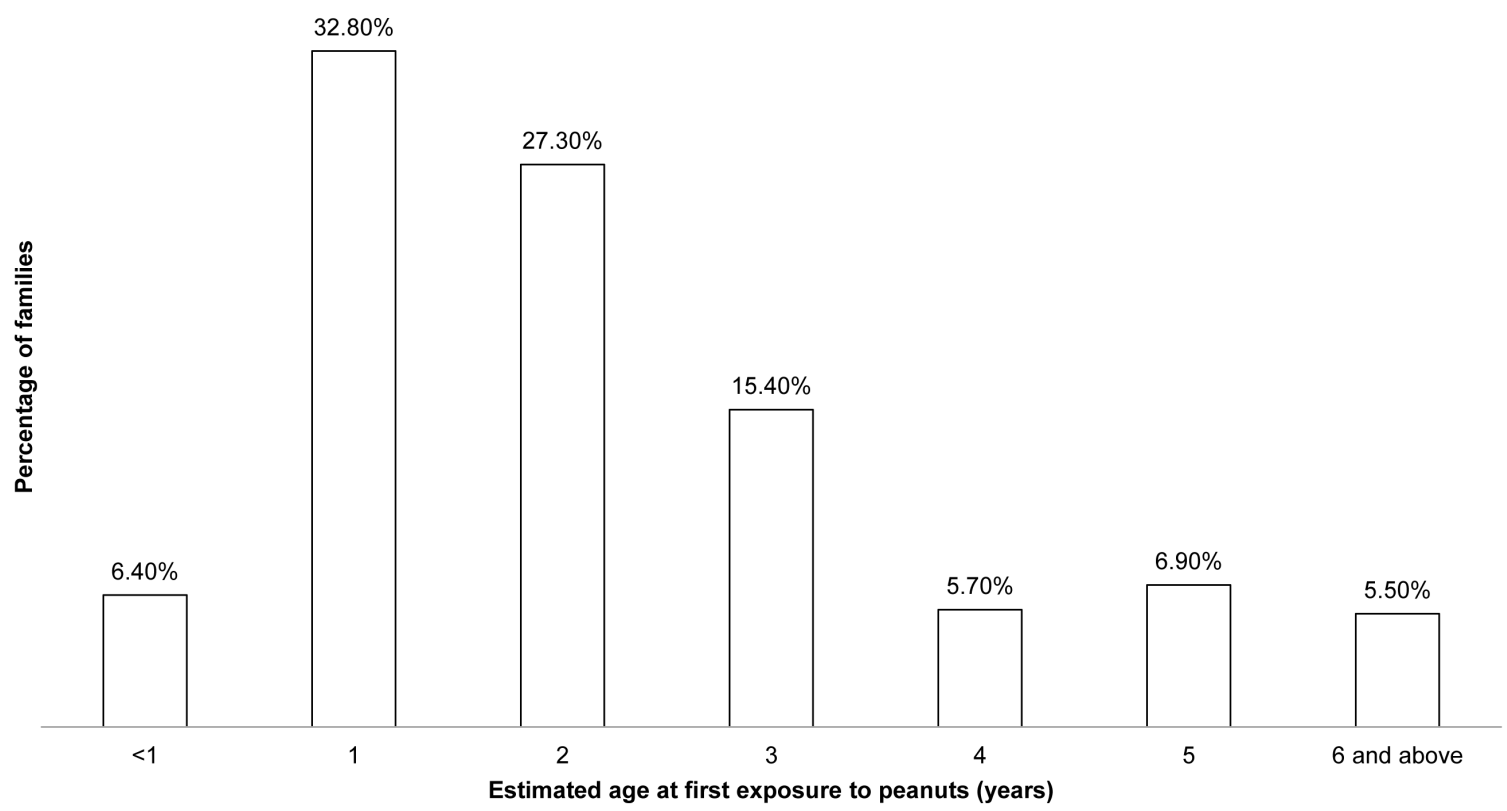

Figure 2. Estimated age of peanut farmers’ offspring at first exposure to peanut-containing food.

The average estimated weekly consumption of peanut varied widely for each child and is shown in Figure 3 . The majority of offspring ate peanuts one to three times per week.

\subsection{Reported Rates of Asthma, Allergic Rhinitis, Atopic Dermatitis, and Other Food Allergy}

The reported rates of other food allergies and atopic conditions are shown in Table 1 . In comparison to the reported rate of PA among all offspring of peanut growers (1.48\%), the reported rates of tree nut, milk and egg allergy were $1.28 \%, 1.6 \%$, and $1.4 \%$, respectively. The reported rates of physician-diagnosed food and environmental allergies in the parents are shown in Table 1. Reported food allergies included peanut, tree nuts, fish, shellfish, milk, egg, wheat, soy, chocolate, vegetables and fruit. Reported environmental allergies included grass, ragweed, dust, mold, animals, and unspecified pollens.

\section{Discussion}

The objective of this questionnaire-based study was to determine the prevalence of peanut allergy (PA) in 


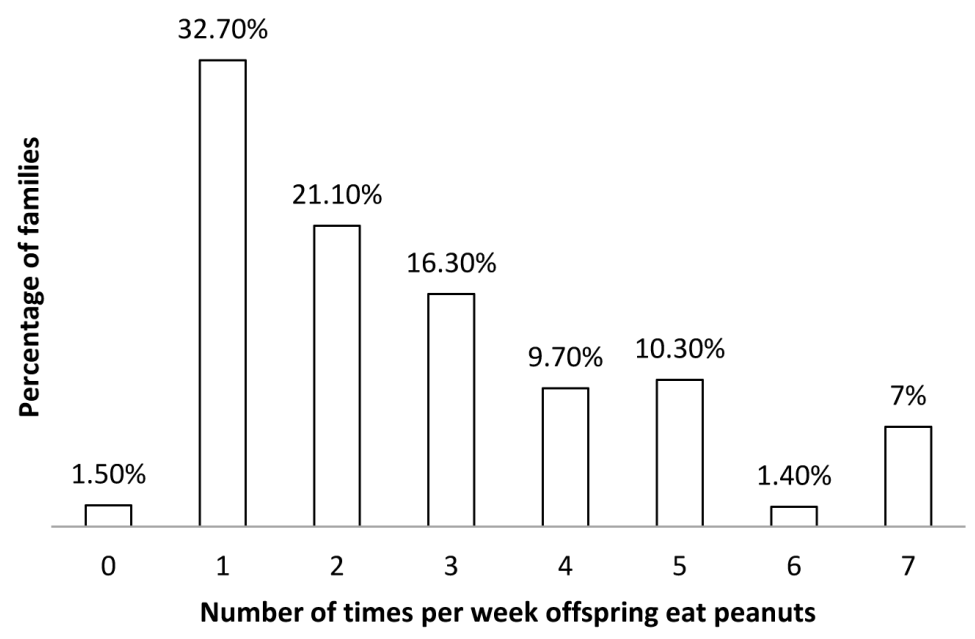

Figure 3. Average frequency of peanut consumption (times/week).

Table 1. Reported rates of peanut allergy, food allergy and atopic conditions in peanut growers families.

\begin{tabular}{|c|c|c|c|c|}
\hline \multirow[b]{2}{*}{ Outcome } & \multicolumn{4}{|c|}{ Self reported rates } \\
\hline & $\begin{array}{c}\text { Offspring } \leq 10 \text { years } \\
(\mathbf{n}=271) \\
\%,(n)\end{array}$ & $\begin{array}{c}\text { Offspring } \leq 15 \text { years } \\
(n=493) \\
\%,(n)\end{array}$ & $\begin{array}{c}\text { All offspring } \\
(\mathbf{n}=2493) \\
\%,(\mathrm{n})\end{array}$ & $\begin{array}{c}\text { Self-reported } \\
\text { prevalence \% (reference) } \\
\text { of children in the general } \\
\text { population }\end{array}$ \\
\hline Asthma & $7.4 \%(20)$ & $9.9 \%(49)$ & $8.5 \%(211)$ & $8.9 \%(23)$ \\
\hline Eczema & $11.4 \%(31)$ & $12.6 \%(68)$ & $6.2 \%(155)$ & $10.7 \%(24)$ \\
\hline Rhinitis & $35.0 \%(95)$ & $37.1 \%(183)$ & $36.9 \%(920)$ & $9.1 \%(27)$ \\
\hline Peanut allergy & $3.69 \%(10)$ & $2.8 \%(14)$ & $1.48 \%(37)$ & \\
\hline $\begin{array}{l}\text { Physician-confirmed } \\
\text { Physician-confirmed and }\end{array}$ & $3.3 \%(9)$ & $2.6 \%(13)$ & $1.24 \%(31)$ & $1.77 \%(1)$ \\
\hline epinephrine autoinjector & $1.8 \%(5)$ & $1.8 \%(9)$ & $0.68 \%(17)$ & \\
\hline Tree nuts & $1.8 \%(5)$ & $1.4 \%(7)$ & $1.28 \%(32)$ & $1.73 \%(1)$ \\
\hline Fish & $0.37 \%(1)$ & $0.2 \%(1)$ & $0.64 \%(16)$ & $0.18 \%(1)$ \\
\hline Shellfish & $1.47 \%(4)$ & $1.0 \%(5)$ & $1.8 \%(45)$ & $0.55 \%(1)$ \\
\hline Milk & $1.8 \%(5)$ & $2.0 \%(10)$ & $1.6 \%(40)$ & $2.23 \%(1)$ \\
\hline Eggs & $2.6 \%(7)$ & $2.0 \%(10)$ & $1.4 \%(35)$ & $1.23 \%(1)$ \\
\hline Wheat & $0.7 \%(2)$ & $0.8 \%(4)$ & $0.6 \%(15)$ & $0.45 \%(1)$ \\
\hline Soy & $0.37 \%(1)$ & $0.6 \%(3)$ & $0.36 \%(9)$ & $0.32 \%(1)$ \\
\hline Parent reported food allergy & - & - & $4.5 \%$ & - \\
\hline $\begin{array}{l}\text { Parent reported environmental } \\
\text { allergy }\end{array}$ & - & - & $10.8 \%$ & - \\
\hline
\end{tabular}

offspring of peanut farmers, a population which, to our knowledge, has not previously been examined. In our study, the reported prevalence of PA ranged from 1.48\% (all offspring) to $3.69 \%$ (offspring $\leq 10$ years). This prevalence rate for peanut allergy, particularly for all offspring, is in the range observed in the literature for the general population. For example, a population-based study in Montreal reported a $1.5 \%$ prevalence of PA in school children based on questionnaires, skin prick tests and measurement of peanut-specific IgE [19]. A large 
US telephone survey found a $1.4 \%$ prevalence of PA in children based on self-reported data and convincing reaction history [2]. In the UK, a 1.8\% prevalence of PA was determined in a cohort of school aged children, based on questionnaires, skin prick tests and double-blind, placebo-controlled food challenge [3]. Our study did not include confirmatory skin prick tests or food challenges, so the reported prevalence of PA in our survey is likely an overestimate of the true prevalence.

Data were separated into three (overlapping, not mutually exclusive) age groups for analysis ( $\leq 10$ years, $\leq 15$ years, and all ages) to assess whether the prevalence of PA was increasing over time in this population. Using the most restrictive case definition requiring both physician confirmation of PA, and prescription of an epinephrine auto-injector, the reported prevalence $(1.8 \%, 1.8 \%$, and $0.68 \%$ for offspring $\leq 10$ years, $\leq 15$ years, and all offspring, respectively) appeared to decrease as the age range increased. These values are similar to self-reported rates in the general population in the USA $(0.9 \%, 1.3 \%$, and $0.7 \%$ for offspring 0 - 5 years, 6 - 10 years, and 11 17 years, respectively) [2]. However, as we included offspring of all ages in our analysis, recall bias was likely introduced as responders from families with younger offspring and more temporally proximal events would have had the benefit of improved recall.

The major limitation of this study was the low response rate of $10 \%$, which is lower than in other survey studies [1] [2]. Given this low response rate, participation bias may have influenced our results leading to either under- or over-estimation of peanut allergy prevalence, and thus we cannot draw firm conclusions from our results.

The second major limitation of this survey-based study is that the outcomes are self-reported. The most restrictive case definition for peanut allergy was report of physician confirmation of PA and prescription of an epinephrine auto-injector device. A more restrictive case definition, such as excluding those in whom the time to onset of allergic symptoms was over 60 minutes could have been used. However, this would not have changed the prevalence as three of the four respondents with prolonged reaction onset also reported that they were not prescribed an epinephrine auto-injector device. The questionnaire specifically elicited a history of "doctor confirmed” asthma and eczema, but did not elicit the same for other self-reported food allergies or parental allergies. The reported rates of tree nut (1.28\%), milk (1.6\%) and egg allergy (1.4\%) were similar to reported prevalence ranges for offspring in the general population, including a recent Canadian survey study which found selfreported food allergy rates for tree nut, milk and egg of 1.73\%, 2.23\%, and 1.23\%, respectively [1] [2] [20] [21]. Although we chose to use the prevalence of egg allergy as a comparator for PA, these food allergies are not independent, as egg allergy is a strong risk factor for sensitization to peanut [22].

There are a number of other possible influences on the results in this population: the rural or farming environment, the potential environmental peanut exposure, and the possibility of greater ease of access to peanut as a food source. Without knowing the exact nature of each peanut farm environment, particularly exposure to stables and farm milk, we cannot draw conclusions about the prevalence of other atopic conditions in comparison to other rural farming populations. The prevalence of some atopic conditions, such as asthma and eczema, are in keeping with the self-reported prevalence (8.9\% and $10.7 \%$, respectively) in the general North American population [23] [24]. However, the prevalence of allergic rhinitis (35\%, 37.1\%, and 36.9\% for offspring $\leq 10$ years, $\leq 15$ years, and all offspring, respectively) was much higher than previously reported rates of $11 \%$ - $13 \%$ in non-farming rural populations [18] [25] [26] as well as the rate of 9.1\% reported in children under age 17 in the general population [27]. This may suggest an increased response rate from those with atopic offspring. However, such a participation bias would be expected to result in an increased rate of other atopic conditions and peanut allergy, which we did not find.

Another confounder is the potential presence of peanut protein in the household environment of peanut farmers, a factor that may influence cutaneous sensitization [10]. Quantification of peanut allergen in the general household environments has been performed in other studies [28] [29]. Recently, levels of household environmental peanut protein were found to correlate with household peanut consumption; and peanut protein in household dust was demonstrated to have biological activity, suggesting that environmental peanut protein may be capable of inducing sensitization [28]. As this was a survey study, we were not able to quantify peanut allergen in the household environment of peanut farmers.

Finally, it is possible that the timing and frequency of peanut consumption may have differed among peanut farmers' offspring in comparison to the general population, as they may have had greater access to peanut as a food source. Du Toit et al. demonstrated a lower prevalence of peanut allergy among Jewish infants in Israel, where peanut is consumed earlier (in the first year of life) and more frequently than in the UK [16]. Previous 
North American guidelines for high risk infants recommended avoidance of peanut during pregnancy and breastfeeding, and delaying oral introduction until age 3 [30]. In the UK, when similar recommendations were in place, the mean age of peanut introduction was 36 months [3]. These recommendations were not in place for many of the offspring in our study population (mean age 26 years), though they may be relevant to the 493/2493 (22\%) of the offspring currently $\leq 15$ years of age. Among all offspring of peanut farmers, $39 \%$ had been introduced to peanut at age 1 year or below, and $81 \%$ by age 3years or below. The fact that $19 \%$ of children had not yet been introduced to peanut by age 3 is concerning for a participation bias towards those with atopic offspring who delayed peanut introduction in accordance with prior guidelines; however, we would have expected to see a relatively increased prevalence of PA and other atopic conditions if this were true. According to the National Peanut Board, the average consumption of peanut products in the US is six pounds per person per year [31]. In our study, $98.5 \%$ of peanut farmers' offspring consumed peanuts on a regular basis, at least once per week.

\section{Conclusion}

We found that the self-reported prevalence of peanut allergy in offspring of peanut farmers was similar to that reported in the general population. Based on previous studies, if peanut allergy were confirmed with skin testing, serological assay or double-blind placebo controlled peanut challenge, the prevalence observed in this survey likely would be lower [8] [19]. A number of factors may have influenced our results, including participation and recall bias inherent to survey studies, and the potential for exposure to household environmental peanut, although we would have hypothesized that these factors would result in a relatively increased PA prevalence, which we did not find. Additional factors such as the rural/farming environment and potential differences in peanut introduction and consumption patterns may have further affected the results. This is a unique North American population that may provide some insight into the factors that influence development of peanut allergy.

\section{Acknowledgements}

Funded by an unrestricted grant from the National Peanut Board to Dr. Peter Vadas.

\section{References}

[1] Ben-Shoshan, M., Harrington, D.W., Soller, L., et al. (2010) A Population-Based Study on Peanut, Tree Nut, Fish, Shellfish, and Sesame Allergy Prevalence in Canada. Journal of Allergy and Clinical Immunology, 125, 1327-1335. http://dx.doi.org/10.1016/j.jaci.2010.03.029

[2] Sicherer, S.H., Muñoz-Furlong, A., Godbold, J.H. and Sampson, H.A. (2010) US Prevalence of Self-Reported Peanut, Tree Nut, and Sesame Allergy: 11-Year Follow-Up. Journal of Allergy and Clinical Immunology, 125, 1322-1326. http://dx.doi.org/10.1016/j.jaci.2010.03.029

[3] Hourihane, J.O., Aiken, R., Briggs, R., et al. (2007) The Impact of Government Advice to Pregnant Mothers Regarding Peanut Avoidance on the Prevalence of Peanut Allergy in United Kingdom Children at School Entry. Journal of Allergy and Clinical Immunology, 119, 1197-1202. http://dx.doi.org/10.1016/j.jaci.2006.12.670

[4] Ho, M.H., Wong, W.H., Heine, R.G., Hosking, C.S., Hill, D.J. and Allen, K.J. (2008) Early Clinical Predictors of Remission of Peanut Allergy in Children. Journal of Allergy and Clinical Immunology, 121, 731-736. http://dx.doi.org/10.1016/j.jaci.2007.11.024

[5] Fleischer, D.M., Conover-Walker, M.K., Christie, L., Burks, A.W. and Wood, R.A. (2003) The Natural Progression of Peanut Allergy: Resolution and the Possibility of Recurrence. Journal of Allergy and Clinical Immunology, 112, 183189. http://dx.doi.org/10.1067/mai.2003.1517

[6] Skolnick, H.S., Conover-Walker, M.K. and Koerner, C.B. (2001) The Natural History of Peanut Allergy. Journal of Allergy and Clinical Immunology, 107, 367-374. http://dx.doi.org/10.1067/mai.2001.112129

[7] Bock, S.A., Muñoz-Furlong, A. and Sampson, H.A. (2001) Fatalities Due to Anaphylactic Reactions to Foods. Journal of Allergy and Clinical Immunology, 107, 191-193. http://dx.doi.org/10.1067/mai.2001.112031

[8] Sicherer, S.H., Burks, A.W. and Sampson, H.A. (1998) Clinical Features of Acute Allergic Reactions to Peanut and Tree Nuts in Children. Pediatrics, 102, e6. http://dx.doi.org/10.1542/peds.102.1.e6

[9] Hourihane, J.O., Kilburn, S.A., Dean, P. and Warner, J.O. (1997) Clinical Characteristics of Peanut Allergy. Clinical Experimental Allergy, 27, 634-639. http://dx.doi.org/10.1111/j.1365-2222.1997.tb01190.x

[10] Fox, A.T., Sasieni, P., du Toit, G., Syed, H. and Lack, G. (2009) Household Peanut Consumption as a Risk Factor for 
the Development of Peanut Allergy. Journal of Allergy and Clinical Immunology, 123, 417-423. http://dx.doi.org/10.1016/j.jaci.2008.12.014

[11] Lack, G., Fox, D., Northstone, K. and Golding, J., Avon Longitudinal Study of Parents and Children Study Team (2003) Factors Associated with the Development of Peanut Allergy in Childhood. New England Journal of Medicine, 348, 977-985. http://dx.doi.org/10.1056/NEJMoa013536

[12] Brown, S.J., Asai, Y., Cordell, H.J., Campbell, L.E., Zhao, Y.W., Liao, H.H., et al. (2011) Loss-of-Function Variants in the Filaggrin Gene Are a Significant Risk Factor for Peanut Allergy. Journal of Allergy and Clinical Immunology, 127, 661-667. http://dx.doi.org/10.1016/j.jaci.2011.01.031

[13] Tan, H.T., Ellis, J.A., Koplin, J.J., Matheson, M.C., Gurrin, L.C., et al., HealthNuts Study (2012) Filaggrin Loss-ofFunction Mutations Do Not Predict Food Allergy over and above the Risk of Food Sensitization among Infants. Journal of Allergy and Clinical Immunology, 130, 1211-1213. http://dx.doi.org/10.1016/j.jaci.2012.07.022

[14] Strid, J., Thomson, M., Hourihane, J., Kimber, I. and Strobel, S. (2004) A Novel Model of Sensitization and Oral Tolerance to Peanut Protein. Immunology, 113, 293-303. http://dx.doi.org/10.1111/j.1365-2567.2004.01989.x

[15] Marth, T., Strober, W. and Kelsall, B.L. (1996) High Dose Oral Tolerance in Ovalbumin TCR-Transgenic Mice: Systemic Neutralization of IL-12 Augments TGF-Beta Secretion and T Cell Apoptosis. Journal of Immunology, 157, 2348-2357.

[16] Du Toit, G., Katz, Y., Sasieni, P., Mesher, D., Maleki, S.J., Fisher, H.R., et al. (2008) Early Consumption of Peanuts in Infancy Is Associated with a Low Prevalence of Peanut Allergy. Journal of Allergy and Clinical Immunology, 122, 984-991. http://dx.doi.org/10.1016/j.jaci.2008.08.039

[17] Remes, S.T., Livanainen, K., Koskela, H. and Pekkanen, J. (2003) Which Factors Explain the Lower Prevalence of Atopy amongst Farmer's Children? Clinical \& Experimental Allergy, 33, 427-434. http://dx.doi.org/10.1046/j.1365-2222.2003.01566.x

[18] Riedler, J., Braun-Fahrländer, C., Eder, W., Schreuer, M., Waser, M., Maisch, S., et al. (2001) Exposure to Farming in Early Life and the Development of Asthma and Allergy: A Cross-Sectional Survey. Lancet, 358, 1129-1133. http://dx.doi.org/10.1016/S0140-6736(01)06252-3

[19] Kagan, R.S., Joseph, L., Dufresne, C., Gray-Donald, K., Turnbull, E., St. Pierre, Y. and Clarke, A.E. (2003) Prevalence of Peanut Allergy in Primary-School Children in Montreal, Canada. Journal of Allergy and Clinical Immunology, 112, 1223-1228. http://dx.doi.org/10.1016/j.jaci.2003.09.026

[20] Soller, L., Ben-Shoshan, M., Harrington, D., Fragapane, J., Joseph, L., St. Pierre, Y., et al. (2012) Overall Prevalence of Self-Reported Food Allergy in Canada. The Journal of Allergy and Clinical Immunology, 130, 986-988. http://dx.doi.org/10.1016/j.jaci.2012.06.029

[21] Osterballe, M., Hansen, T.K., Mortz, C.G., Høst, A. and Bindslev-Jensen, C. (2005) The Prevalence of Food Hypersensitivity in an Unselected Population of Children and Adults. Pediatric Allergy and Immunology, 16, 567-573. http://dx.doi.org/10.1111/j.1399-3038.2005.00251.x

[22] Du Toit, G., Roberts, G., Sayre, P.H., Plaut, M., Bahnson, H.T., Mitchell, H., et al. (2013) Identifying Infants at High Risk of Peanut Allergy: The Learning Early about Peanut Allergy (LEAP) Screening Study. Journal of Allergy and Clinical Immunology, 131, 135-143. http://dx.doi.org/10.1016/j.jaci.2012.09.015

[23] Akinbami, L., Centers for Disease Control and Prevention, National Center for Health Statistics (2006) The State of Childhood Asthma, United States, 1980-2005. Advance Data, 381, 1-24.

[24] Shaw, T.E., Currie, G.P., Koudelka, C.W. and Simpson, E.L. (2011) Eczema Prevalence in the United States: Data from the 2003 National Survey of Children's Health. Journal of Investigative Dermatology, 131, 67-73. http://dx.doi.org/10.1038/jid.2010.251

[25] Remes, S.T., Koskela, H.O., Iivanainen, K. and Pekkanen, J. (2005) Allergen-Specific Sensitisation in Asthma and Allergic Diseases in Children: The Study on Farmers' and Non-Farmers' Children. Clinical \& Experimental Allergy, 35, 160-166. http://dx.doi.org/10.1111/j.1365-2222.2005.02172.x

[26] Braun-Fahrländer, C., Gassner, M., Grize, L., et al. (1999) Prevalence of Hay Fever and Allergic Sensitization in Farmers' Children and Their Peers Living in the Same Rural Community: SCARPOL Team-Swiss Study on Childhood Allergy and Respiratory Symptoms with Respect to Air Pollution. Clinical \& Experimental Allergy, 29, 28-34. http://dx.doi.org/10.1046/j.1365-2222.1999.00479.x

[27] Meltzer, E.O. (1997) The Prevalence and Medical and Economic Impact of Allergic Rhinitis in the United States. Journal of Allergy and Clinical Immunology, 99, S805-S828.

[28] Brough, H.A., Santos, A.F., Makinson, K., Penagos, M., Stephens, A.C., Douiri, A., et al. (2013) Peanut Protein in Household Dust Is Related to Household Peanut Consumption and Is Biologically Active. Journal of Allergy and Clinical Immunology, 132, 630-638. http://dx.doi.org/10.1016/j.jaci.2013.02.034

[29] Perry, T.T., Conover-Walker, M.K., Pomes, A., Chapman, M.D. and Wood, R.A. (2004) Distribution of Peanut Aller- 
gen in the Environment. Journal of Allergy and Clinical Immunology, 113, 973-976. http://dx.doi.org/10.1016/j.jaci.2004.02.035

[30] American Academy of Pediatrics Committee on Nutrition (2000) Hypoallergenic Infant Formulas. Pediatrics, 106, 346-349. http://dx.doi.org/10.1542/peds.106.2.346

[31] National Peanut Board, Fun Facts. http://nationalpeanutboard.org/the-facts/fun-facts/ 
Scientific Research Publishing (SCIRP) is one of the largest Open Access journal publishers. It is currently publishing more than 200 open access, online, peer-reviewed journals covering a wide range of academic disciplines. SCIRP serves the worldwide academic communities and contributes to the progress and application of science with its publication.

Other selected journals from SCIRP are listed as below. Submit your manuscript to us via either submit@scirp.org or Online Submission Portal.
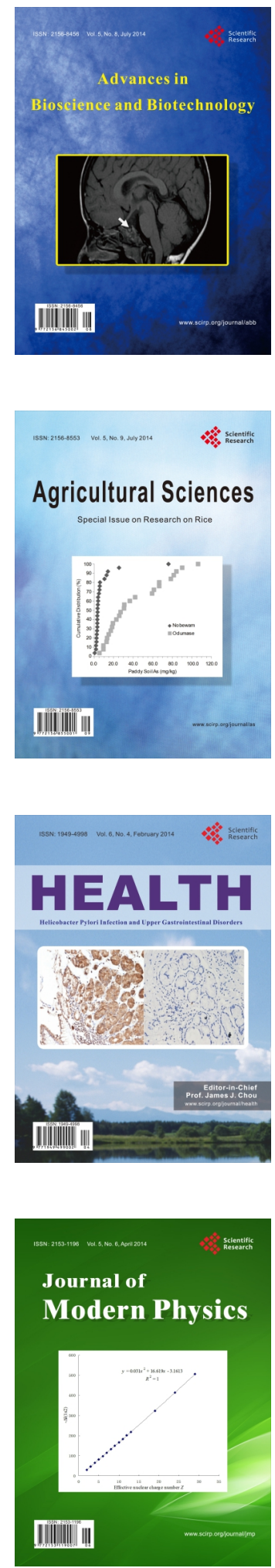
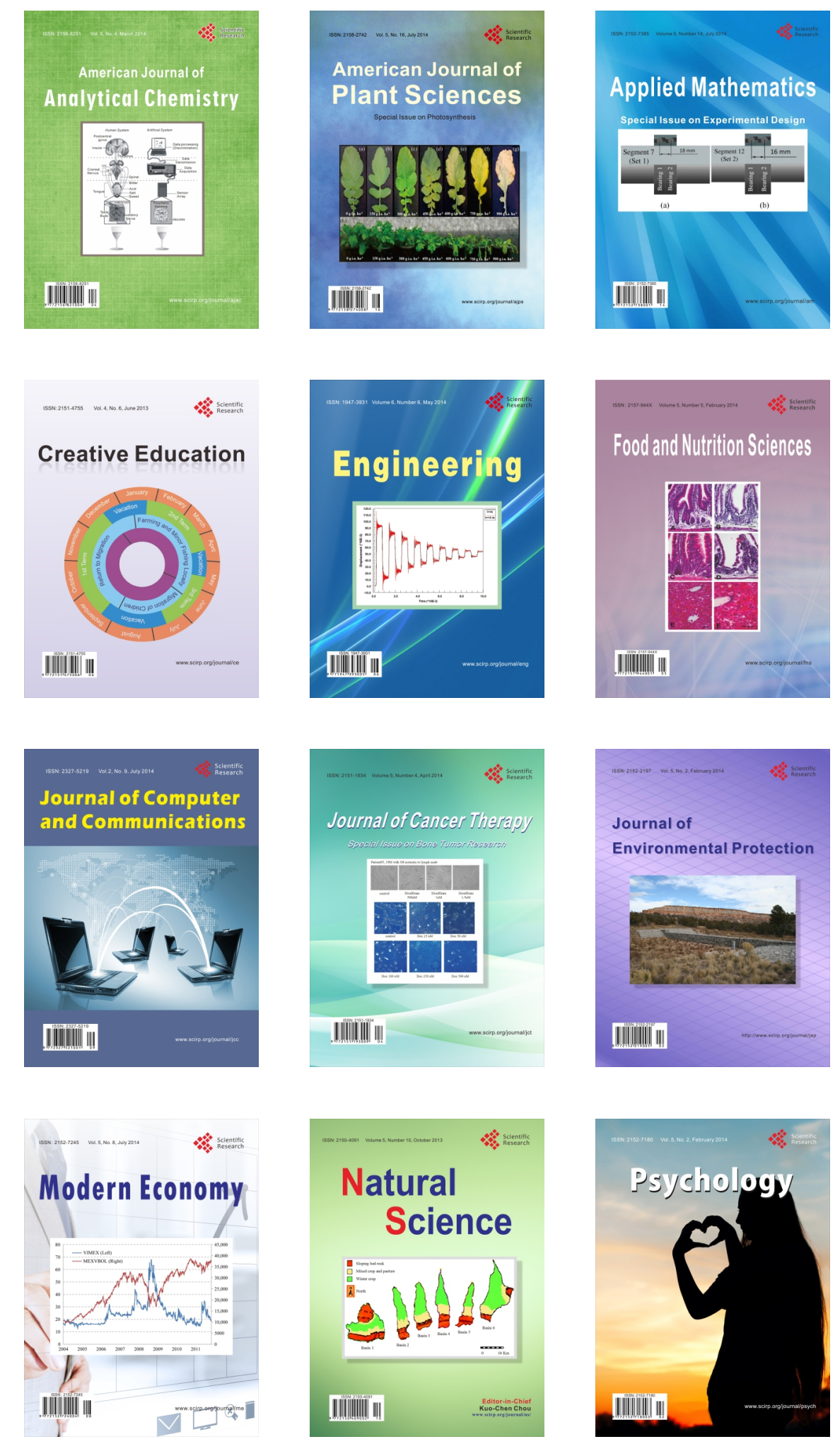